\title{
Lightweight Concrete Using Oil Palm Boiler Clinker (OPBC) - A Review
}

\author{
Herry Hartono ${ }^{1}$, Lee Jin Chai ${ }^{1}$ and B. C. T. Lee ${ }^{1, a}$ \\ ${ }^{1}$ Department of Engineering, UCSI University, Cheras, 56000 Kuala Lumpur, Malaysia
}

\begin{abstract}
Lightweight concrete can be effectively produced by replacing normal aggregates ( $60 \%$ to $75 \%$ of concrete volume) with a lighter alternative. With depleting natural resources, utilising waste materials, such as oil palm boiler clinker (OPBC), in concrete for structural use is one way to mitigate environmental concerns raised by the construction industry. This paper presents a review of the mechanical properties, structural behaviour and performance of OPBC concrete. Lightweight concrete using $\mathrm{OPBC}$ can be designed to achieve different compressive strengths with different mixes. The different OPBC concrete mixes result in different densities and workability. The degree of content and the type of OPBC substitutes used affect the flexural strength and 28-day splitting tensile strength of OPBC concrete. A different effect was observed in the modulus of elasticity as the drying shrinkage and water absorption of OPBC concrete are also impacted. This review study also compares the structural performance of OPBC concrete to that of conventional concrete.
\end{abstract}

\section{Introduction}

The need to meet the demand for concrete from the construction sector raises environmental concerns. The resulting carbon dioxide emission is making concrete industry to be not sustainable [1], and construction activities to be labelled as not "green" [2]. Concrete manufacturing also consumes high amount of natural aggregates, accounting for $70 \%-80 \%$ of total concrete volume [3]. The concrete industry has been known to be the largest contributor to the depletion of limited natural resources i.e. sand, water, rock, and gravel [4].

Because concrete is essentially a blend, the constituents can therefore be selected to enable the maximisation and optimisation of concrete's performance [5]. To curb the issue on environmental concerns, artificial aggregates e.g. fly ash, ground granulated blast furnace slag, and expanded clay, can be used as substitutes to produce an environmentally friendly lightweight concrete [6]. By using lightweight aggregates in concrete, lightweight concrete can be produced.

Concrete is considered as lightweight when its density ranges between $1440 \mathrm{~kg} / \mathrm{m}^{3}$ to $1840 \mathrm{~kg} / \mathrm{m}^{3}$. The density of conventional concrete lies between $2240 \mathrm{~kg} / \mathrm{m}^{3}$ to $2400 \mathrm{~kg} / \mathrm{m}^{3}$. Despite the lower densities, lightweight concrete is still expected to have a compressive strength of at least $17.0 \mathrm{MPa}$ for use on structures [7].

The weight of lightweight concrete is about $25 \%$ to $35 \%$ less than conventional concrete [8]. With the use of lightweight concrete, the reduction in dead load is approximated to be $20 \%$, which can be

\footnotetext{
${ }^{a}$ Corresponding author : brendalee@ucsiuniversity.edu.my
} 
translated to about $10 \%$ of construction cost saving [9]. The reduction of dead weight consequently allows the reduction in size of load bearing elements as well as the use of steel reinforcement. Lightweight concrete also possesses a low coefficient of thermal expansion and a better fire-resistant as compared to normal weight concrete. It is therefore possible to construct a thinner fire rating slab which leads to a lighter building and lower construction cost [10].

By using low-cost lightweight aggregate, the production cost of lightweight concrete is also reduced. This has been shown possible with the successful substitution of aggregates with agricultural wastes for lightweight concrete production [11]. One of the agricultural wastes is OPBC [12]. OPBC usually has no economic value and are plentifully available [13]. Full aggregate substitution with OPBC has been shown to reduce $30 \%$ of manufacturing cost and $22.62 \%$ reduction in carbon dioxide emission, with comparable structural efficiency (strength-to-weight ratio) to conventional mix concrete [14].

\section{Lightweight Concrete using Agricultural Waste as Aggregates}

Lightweight concrete that is made with lightweight aggregate can be categorised into two categories based on its formation: (1) mechanical treatment and (2) thermal treatment. Lightweight concrete that uses agricultural waste as aggregates is grouped in the latter category, where aggregate is produced using combustion of natural or waste material. These aggregates can be made of coconut shell, rice husk, corn cob, tobacco waste, oil palm shell and OPBC as examples [11].

There is always a challenge in attaining high strength in lightweight concrete, i.e. compressive strength of above $55.0 \mathrm{MPa}$, due to its porosity that tends to restrain the development of mechanical properties of the concrete [15-18]. Despite that, lightweight concrete produced using agricultural wastes as coarse aggregate has been shown to be able to achieve high compressive strength. The 28 days compressive strength of lightweight concrete using crushed oil palm shell in saturated surface dry (SSD) condition was found to be $53.0 \mathrm{MPa}$ [19]. This was achieved by having water-cement ratio of 0.45 . When a lower water-cement ratio was used, i.e. 0.35 , the 28 days compressive strength was found to be $42.5 \mathrm{MPa}$ [20].

\subsection{Lightweight concrete using OPBC as aggregates}

OPBC stones are obtained from the combustion of palm oil fibre and palm oil shell. They are irregular in shape and thorny. The OPBC stones are usually grey in colour and are porous. Figure 1 shows the form of OPBC stones in coarse and fine sizes. OPBC particles that pass $4.75 \mathrm{~mm}$ sieve are used for fine aggregate replacement whereas the particles that has nominal size of $20 \mathrm{~mm}$ (above $4.75 \mathrm{~mm}$ ) are used for coarse aggregate replacement [12]. Besides coarse and fine aggregates, OPBC can be ground into finer sizes, to be used as binder replacement [14].

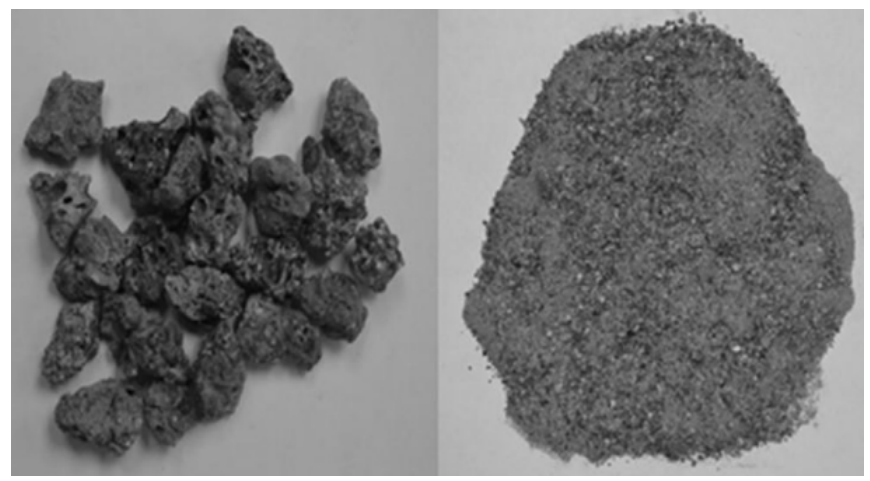

Figure 1. Coarse and fine OPBC [14]. 


\subsection{Mix design}

In the mix design, normal weight aggregate is usually substituted with OPBC by volume because $\mathrm{OPBC}$ is much lighter than normal weight aggregate. Like other lightweight aggregates, OPBC is porous, making it to be sensitive to water content. The use of OPBC in place of coarse and fine aggregates in lightweight concrete has been shown to achieve a 28-day compressive strength of 44.4 $\mathrm{MPa}$ in pre-stressed beams. This mix had a water-cement ratio of 0.44 [21]. With a higher watercement ratio of 0.55 , and the use of $10 \%$ fly ash, the strength was found to be $42 \mathrm{MPa}$ [12].

At higher water-cement ratios, when OPBC concrete is mixed in accordance to ACI 211.2-98, the expected 28-day compressive strength was in the range of 17.00 to $33.17 \mathrm{MPa}$ [22]. When mixed according to conventional mix design (ACI method), even if OPBC is used only as fine aggregates, it yielded lower compressive strength and workability [23].

In more recent studies, the highest 28-day strength was found in a mix that has even lower watercement ratio of 0.38 , which is $42.56 \mathrm{MPa}$ [24]. For a mix that uses OPBC only as coarse aggregates and water-cement ratio of 0.331 , the 28 -day compressive strength was found to be about $5 \%$ higher at 44.89 MPa [25]. The latter, however, uses plasticizer to improve the workability of the mix.

When designed to be self-compacting concrete mix, OPBC concrete was found to be able to achieve 28-day compressive strength in the range of 50.0-60.0 $\mathrm{MPa}$. This mix was designed with water-cement ratios of 0.43 to 0.54 , and included a stage in the process where OPBC was immersed for 24 hours for absorption of water [26]. Then, it was shown that it is also possible for selfcompacting OPBC concrete to be produced with 28-day compressive strength of between 60.0 to 70.0 $\operatorname{MPa}[14]$.

\section{Physical and Mechanical Performance}

\subsection{Slump}

For concrete that uses OPBC as coarse and fine aggregates, slump values of 85 to $125 \mathrm{~mm}$ could be achieved with $10 \%$ inclusion of fly ash as binder material [12]. With the addition of superplasticizer, a high workability mix (slump of $102 \mathrm{~mm}$ to $127 \mathrm{~mm}$ ) was yielded for up to $37.5 \%$ of fine OPBC in the mix [25]. However, a reduced slump value of $50 \mathrm{~mm}$ to $80 \mathrm{~mm}$ was found in concrete incorporating up to $37.5 \%$ of OPBC aggregate (SSD condition) [13].

\subsection{Density}

Weight of concrete was observed to have reduced from $16 \%-23 \%$ when different mixes of OPBC concrete were tested. The greatest reduction was found in the mix that uses OPBC as coarse and fine aggregates [12].

The use of OPBC in concrete reduces the density of concrete due to it being lighter than any of constituents of a concrete mix. For instance, the weight of OPBC sand is $22 \%$ lower than normal sand, that when used, was found to reduce the density of concrete up to $27 \%$ [13]. Similar range of densities was also found when OPBC concrete was mixed with oil palm shell as the replacement for the conventional coarse aggregate: $1889 \mathrm{~kg} / \mathrm{m} 3$ to $1948 \mathrm{~kg} / \mathrm{m} 3$ [25].

The reduction in density of concrete is directly proportional to the ratio of OPBC being used as replacement. A $100 \%$ replacement was found to reduce the density of concrete by $17 \%$ [14]. By comparing the effects caused by the use of OPBC in concrete, the use of OPBC as fine aggregate causes more reduction in concrete density. This may be attributed to the greater number of pores that exists in $\mathrm{OPBC}$ in the form of fine aggregates. 


\subsection{Compressive strength}

The use of OPBC as fine aggregate was found to increase the compressive strength of concrete even at only $5 \%$ of OPBC [27]. However, this was only observed for OPBC concrete mixes under various partial early curing conditions due to the ability of internal curing of OPBC aggregates. When these mixes undergo continuous moist curing, only the mix with $25 \%$ of OPBC was able to achieve compressive strength of $37.4 \mathrm{MPa}$, almost equivalent to that without OPBC, which was $37.8 \mathrm{MPa}$.

The rest have shown a reduction in compressive strength [13].

When used as coarse aggregate, a high compressive strength was attained, i.e. $44.89 \mathrm{MPa}$ [25]. The difference in effects when OPBC is used as coarse compared to as fine aggregates is due to the greater number of pores in fine OPBC [12].

A different phenomenon was observed when OPBC is used as partial and whole replacement of coarse aggregate, fine aggregate and binder material in self-compacting concrete. The compressive strength was found to be in the range of $60.0 \mathrm{MPa}$ to $70.0 \mathrm{MPa}$. These values of compressive strength can still be achieved despite the $100 \%$ substitution of OPBC as fine and coarse aggregate [14].

\subsection{Flexural strength}

A similar trend to that of compressive strength is found in the effects that OPBC has in concrete on its flexural strength. It was found that there was an increase of $28 \%$ in flexural strength when OPBC is used as 5\% of fine aggregates, and an increase of 33\% when used as $10 \%$ [27]. The opposite effect was found when more than $10 \%$ of fine aggregates were replaced with OPBC. The flexural strength of $\mathrm{OPBC}$ concrete decreases as the content of OPBC in the concrete increases [13].

The negative effect was also observed when OPBC is used as both coarse and fine aggregates. When used only as coarse aggregates, the reduction in flexural strength was found to be $20.2 \%$. The effect is greater when OPBC is used also as fine aggregates, causing a reduction of $32.3 \%$ in flexural strength. This can be attributed to the porous characteristic of OPBC [12].

\subsection{Splitting tensile strength}

The minimum 28-day splitting tensile strength of structural lightweight concrete is $2.0 \mathrm{MPa}$ [28]. Although the using of OPBC in concrete is expected to reduce the splitting tensile strength of concrete due the weaker grain in OPBC aggregates [29], OPBC concrete is still found to be suitably used as structural lightweight concrete. For concrete that has $\mathrm{OPBC}$ as fine aggregates, the splitting tensile strength was only reduced by about $2.7 \%$. This reduction increases as the content of OPBC increases up to $50 \%$ [13]. A higher reduction was observed when OPBC was used as both coarse and fine aggregates (up to $32.9 \%$ ) as compared to when it was used only as coarse aggregates (from $23.5 \%$ ) [12].

\subsection{Modulus of elasticity}

The typical modulus of elasticity of structural lightweight concrete is $10.0 \mathrm{GPa}$ to $24.0 \mathrm{GPa}$ [30]. OPBC concrete that uses OPBC as fine aggregates above $37.5 \%$ was found to have modulus of elasticity lower than the required values $[13,25]$. OPBC concrete that uses OPBC as coarse aggregates, on the other hand, has high modulus of elasticity, $81.6 \%$ higher than that of OPBC as $25 \%$ of fine aggregate, at $22.95 \mathrm{GPa}$ [25].

\subsection{Shrinkage}

A higher drying shrinkage in lightweight concrete is expected due to a lower elastic modulus of the aggregate used [31]. This was observed when OPBC is used as coarse and fine aggregates with $10 \%$ 
of fly ash when compared to conventional concrete mix [32]. The use of OPBC as fine aggregate, on the other hand, was found to have no significant effect on the drying shrinkage of concrete [13].

\subsection{Water absorption}

The increased porosity in lightweight aggregate causes higher water absorption [33]. This was coherently found in OPBC concrete mix that uses OPBC as fine aggregate and water absorption increases proportionately with the amount of OPBC in concrete [13]. The 24 hours water absorption of fine and coarse OPBC aggregate was 3.60\% [13] and 3.56 [34]. As most good performance concrete has water absorption value below $10 \%$ by mass [31], the recommended substitution of OPBC is therefore not to exceed $37.5 \%$ in oil palm shell concrete [13].

\section{Structural Performances}

\subsection{Flexural behaviour}

OPBC concrete beams when cast with the reinforcement ratio less than $0.5 \%$ and as pre-stressed were found to behave similarly to normal weight concrete beams. The failure of the beams was due to ductile failure, as expected in normal weight concrete beams [21, 24].

The experimental deflection values for OPBC concrete beams with reinforcement was found to be $10 \%$ to $45 \%$ less than what was expected according to BS 8110 . The resulting crack widths for these specimens were also found to be within the acceptable limit in accordance to BS8110 [24].

For OPBC pre-stressed concrete beams, greater deflection was found when compared to that caused in normal weight concrete, as expected. This difference in deflection is translated to only a drop of mere $6.4 \%$ in carrying capacity [21].

\subsection{Shear behaviour}

The shear failure mode in OPBC concrete beam was found to be similar to that of normal weight concrete beams and is in accordance to ASTM: C330 for structural use [24].

\section{Summary}

The use of OPBC in lightweight concrete has shown promising outcomes. The disadvantages of using OPBC in concrete due to its porosity can be lessened if OPBC is used in certain conditions, size, and percentage of volume. In spite of its sensitivity to water content, its weight brings more advantages to the concrete and construction industry. OPBC concrete, despite being lightweight, can be designed to achieve adequate compressive strength for structural application. The decrease in dead load means cost savings in the construction industry without compromising on structural integrity. The lowered flexural strength in OPBC concrete beams still qualifies itself for use as structural lightweight concrete.

By using OPBC as part of raw materials in concrete also makes the production of OPBC concrete to be more "green' as it calls for less demand for non-renewable natural resources and on top of that, makes use of waste. The cost of OPBC being very low at RM 0.020 per $\mathrm{kg}$ [14], can significantly reduce the cost of concrete.

Lightweight concrete using OPBC can potentially be widely used in the construction industry when optimum ratios of OPBC in different forms can be found to achieve desirable outcomes. More studies could perhaps be conducted to look into the durability of OPBC concrete for these findings to be more conclusive. 


\section{References}

[1] A.A. Ramezanianpour, M.M. Khani and G.H. Ahmadibeni, The effect of rice husk ash on mechanical properties and durability of sustainable concretes, Int. J. of Civil Engineering, 7(2), 83-91, (2009).

[2] V.W.Y. Tam, Comparing the implementation of concrete recycling in the Australian and Japanese construction industries, J. of Cleaner Production, 17, 688-702, (2009).

[3] T.Y. Tu, Y.Y. Chen and C.L. Hwang, Properties of HPC with recycled aggregates, Cement and Concrete Research, 36, 943-950, (2006).

[4] H. Mefteh, O. Kebaili, H. Oucief, L. Berredjem and N. Nourredine Arabi, Influence of moisture conditioning of recycled aggregates on the properties of fresh and hardened concrete, J. of Cleaner Production, 54, 282-288, (2013).

[5] R.N. Swamy, Design for sustainable development of concrete construction. Proc. $4^{\text {th }}$ Int. Structural Engineering and Construction Conference, Taylor and Francis, London, 1241-1246, (2008).

[6] T.W. Bremner, Environmental aspects of concrete: Problems and solutions. Proc. of the 1st Russian Conf. on Concrete and Reinforced Concrete Problems, Moscow, Russia, (2001).

[7] National Ready Mixed Concrete Association, Structural Lightweight Concrete, $<$ http://www.nrmca.org/aboutconcrete/cips/36p.pdf> (accessed 31 January 2015).

[8] T.A. Holm and J.P. Ries, Benefits of Lightweight HPC, $<$ http://www.escsi.org/uploadedFiles/Technical_Docs/Structural_Lightweight_Concrete/4700.9\% 20Benefits\%20of\%20Lightweight\%20HPC.pdf $\$$ (accessed 3 February 2015).

[9] G.K. Mackie, Recent Uses of Structural Lightweight Concrete. $<\mathrm{http}: /$ www.concreteconstruction.net/Images/Recent\%20Uses\%20of\%20Structural\%20Lightwei ght \%20Concrete_tcm45-341131.pdf $>$ (accessed 3 February 2015).

[10]D.P. Martin, A.S. Zimmer, M.J. Bolduc and E.R. Hopps, Is Lightweight Concrete All Wet, $<$ http://www.structuremag.org/?p=1163> (accessed 25 July 2015).

[11]P. Shafigh, H.B. Mahmud, M.Z. Jumaat and M. Zargar, Agricultural wastes as aggregate in concrete mixtures - A review, Construction and Building Materials, 53, 110-117, (2014).

[12] M.H. Ahmad, S. Mohd and M.M. Nurazuwa, Mechanical properties of palm oil clinker concrete,

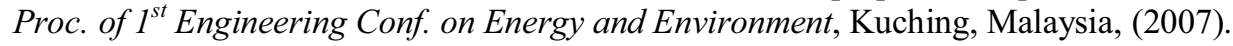

[13]P. Shafigh, H.B. Mahmud, M.Z. Jumaat, R. Ahmmad and S. Bahri, Structural lightweight aggregate concrete using two types of waste from the palm oil industry as aggregate, J. of Cleaner Production, 80, 187-196, (2014).

[14]J. Kanadasan and H.A. Razak, Engineering and sustainability performance of self-compacting palm oil mill incinerated waste concrete, J. of Cleaner Production, 89, 79-86, (2015).

[15]American Concrete Institute, Guide for Structural Lightweight-Aggregate Concrete, ACI Committee Report 213R-03, Michigan, United States, (2003).

[16]American Concrete Institute, Building Code Requirements for Structural Concrete and Commentary, ACI Committee Report 318-11, Michigan, United States, (2011).

[17]H. Costa, E. Julio and J. Lourenco, New approach for shrinkage prediction of high-strength lightweight aggregate concrete, Construction and Building Materials, 35, 84-91, (2012).

[18] M. Lopez and L. Kahn, High performance lightweight concrete - A comparison between actual prestress losses and design code estimates, Revista Ingenieria de Construccion, 22, 59-69, (2007).

[19]P. Shafigh, M.Z. Jumaat, H.B. Mahmud and U.J. Alengaram, A new method of producing high strength oil palm shell lightweight concrete, Materials and Design, 32, 4839-4843, (2011).

[20]H.B. Mahmud, P. Shafigh and M.Z. Jumaat, Structural lightweight aggregate concrete containing high volume waste materials, Key Engineering Materials, 594-595, 498-502, (2014).

[21] W. Omar and R.N. Mohamed, The performance of pretensioned prestressed concrete beams made with lightweight concrete, J. Kejuruteraan Awam, 14(1), (2002).

[22] M. Abdullahi, H.M.A. Al-Mattarneh, A.H.A. Hassan, M.H. Hassan and B.S. Mohammed, Trial mix design methodology for palm oil clinker (POC) concrete, The International Conference on Construction and Building Technology, Kuala Lumpur, (2008). 
[23]M.A. Mannan and K. Neglo, Mix design for oil-palm-boiler clinker (OPBC) concrete, J. of Science and Technology, 30, 111-118, (2010).

[24]B. Mohammed, W.L. Foo and M. Abdullahi, Flexural strength of palm oil clinker concrete beams, Materials and Design, 53(16), 325-331, (2014).

[25]R. Ahmmad, M.Z. Jumaat, S. Bahri and A.B.M.S. Islam, Ductility performance of lightweight concrete element containing massive palm shell clinker, Construction and Building Materials, 53, 234-241, (2014).

[26] J. Kanadasan and H.A. Razak, Mix design for self-compacting palm oil clinker concrete based on particle packing, Materials and Design, 56, 9-19, (2014).

[27]E.A.W. Shahreen, R. Omar, S.F.C. Osmi, N.A.M. Khairussaleh and A. Abdullah, Preliminary study on mechanical properties of concrete added with fine palm oil clinker, University Malaysia Pahang, Malaysia.

[28]N.U. Kockal and T. Ozturan, Strength and elastic properties of structural lightweight concretes, Materials and Design, 32, 2396-2403, (2011).

[29]K.R. Wu, B. Chen, W. Yao, and D. Zhang, Effect of coarse aggregate type on mechanical properties of high-performance concrete, Cement and Concrete Research, 31, 1421-1425, (2001).

[30] CEB/FIP Manual of Design and Technology, Lightweight Aggregate Concrete, The Construction Press, Lancaster, United Kingdom, (1977).

[31]A.M. Neville and J.J. Brooks, Concrete Technology, Pearson Education Asia, Kuala Lumpur, Malaysia, (2008).

[32] M.H. Ahmad, L.Y. Loon, N.M. Noor and S.H. Adnan, Shrinkage of Malaysian palm oil clinker concrete, International Conference on Civil Engineering Practice, Kuantan, (2008).

[33]T.Y. Lo, H.Z. Cui, W.C. Tang and W.M. Leung, The effect of aggregate absorption on pore area at interfacial zone of lightweight concrete, Construction and Building Materials, 22, 623-628, (2008).

[34]R. Ahmmad, Z.M. Jumaat, A.U. Johnson, S. Bahri, M.A. Rehman and H.Hashim, Performance evaluation of palm oil clinker as coarse aggregate in high strength lightweight concrete, J. of Cleaner Production, 112( 1), 566-574, (2016). 